\title{
Modified bowl geometry for cluster nozzles in direct-injection diesel engines
}

\author{
H W Won* and N Peters \\ Institute for Combustion Technology, RWTH Aachen University, Aachen, Germany
}

The manuscript was received on 8 September 2009 and was accepted after revision for publication on 24 February 2010.

DOI: 10.1243/09544070JAUTO1371

\begin{abstract}
A combination of high-pressure injection and small orifices will be one of the strategies to achieve lean combustion. However, equispaced small orifices tend to increase soot under high-load conditions because the spray penetration becomes exceedingly inadequate. For this reason, the cluster concept was chosen as the means to realize lean combustion. To make the use of clusters in a diesel engine feasible, a significant redesign of the typical incylinder geometry would probably be required to promote efficient air utilization. The new combustion chamber was designed with a smaller diameter and deeper bowl. It is expected to improve fuel-air mixing by better spray guidance. The study identifies the aspects of combustion and pollution formation that are affected by mixing processes and offers guidance for better matching of the piston geometry with the spray plume geometry for enhanced mixing. Various clusters were investigated to achieve variation in the injection timing for different test points in the original piston bowl chamber and the new bowl chamber, and the results are compared with those for a conventional nozzle. The cluster with the best results for smoke emissions in the first set of tests was also tested for different swirl ratios and different nozzle protrusion lengths.
\end{abstract}

Keywords: modified bowl geometry, cluster nozzles, direct-injection diesel engines

\section{INTRODUCTION}

Recently, two combustion chamber types have been prominent for diesel engines, namely the 're-entrant chamber' and 'shallow-dish chamber' bowl geometries.

A re-entrant bowl shape is shown in Fig. 1(A). The re-entrant shape strongly affects the fuel distribution along the combustion chamber wall and air-fuel mixing and therefore affects the emissions and performance. A shallow dish bowl shape is shown in Fig. 1(B). This system is used more commonly for heavy-duty applications because the prevailing highpressure common-rail fuel injection system permits greater flexibility in the injection rate and energy available to promote mixing. The spray tip penetration increases as the injection pressure increases. A

*Corresponding author: Institute for Combustion Technology, RWTH Aachen University, Templergraben 64, Aachen 52056, Germany.

email: h.won@itv.rwth-aachen.de large-diameter chamber is required to allow more free spray travel, achieving a better fuel-air mixing and reducing the wall impingement and therefore the soot formation $[\mathbf{1}, \mathbf{2}]$.

For deep-bowl geometries, it was reported that a bowl with a round re-entrant lip shape has about 20 per cent longer spray path length than one without a re-entrant shape [3]. With a re-entrant-type bowl, the spray targeting is a very important parameter for optimal fuel-air mixing. A higher than optimal impingement point will deliver too much fuel to the cylinder head side, causing quenching at the head clearance, while too low an impingement point will deliver too much fuel over the floor of the piston bowl, causing poor mixing with air owing to the lack of air near the centre of the combustion chamber. The optimal impingement strongly depends on the engine speed, the injection system, and the combustion chamber diameter [4].

Lin et al. [5] tested the effects of piston bowl shape on in-cylinder airflow and combustion. They reported on squish and reverse-squish flow for a re- 

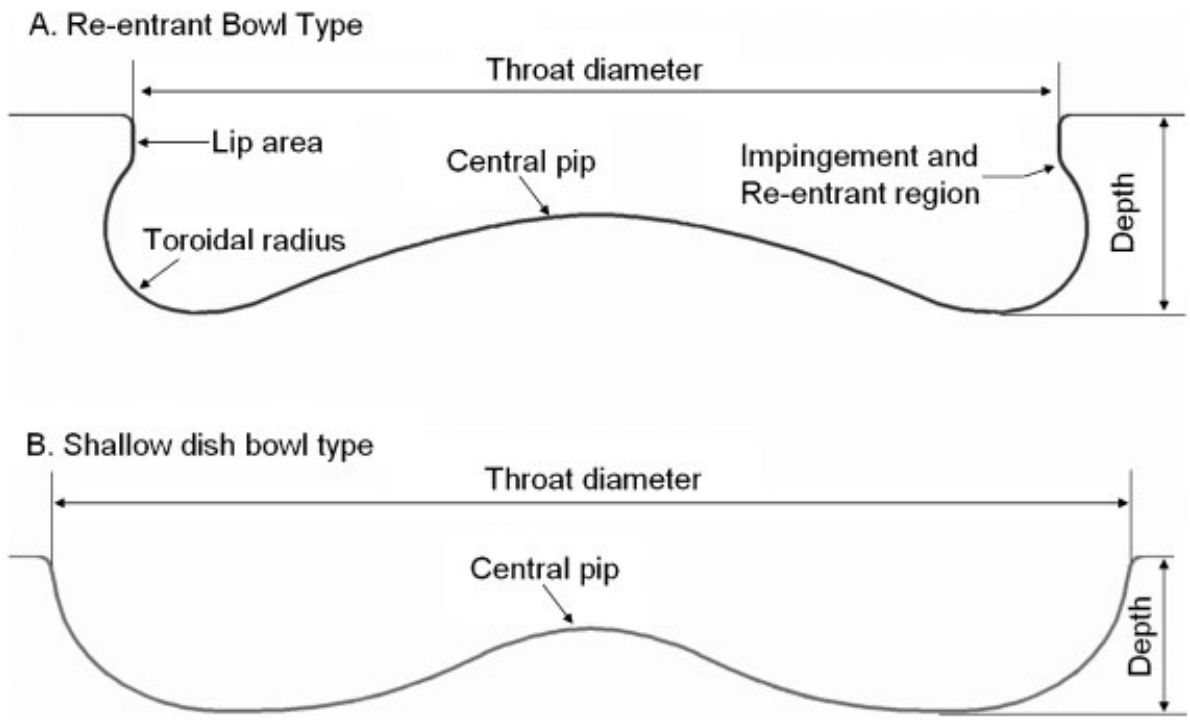

Fig. 1 Re-entrant bowl shape and shallow-dish bowl shape

entrant piston bowl similar to that used in the current study. They showed that the squish flow induces high flow velocities and high turbulence in the whole bowl. Dahlén [6] performed a computational fluid dynamics simulation without injection and combustion to demonstrate how the in-cylinder gas flow affects fuel that is located on the piston bowl wall. It shows that the reverse-squish flow aids the mixing of fuel that is accumulated on the bowl rim. Fuel located below the rim mixes much more slowly with the surrounding air. An effect of the fairly quiescent situation along the wall under the rim during expansion is that a relationship between how the fuel is distributed along the wall and the subsequent flow of flames into the squish region should be expected, presumably because the heavy impact of sprays on to the piston bowl wall builds up the thickest 'blob' of fuel. This fuel then easily moves with the reverse-squish flow into the squish region and combusts as it mixes with air.

Zhu et al. [7] studied the effects of the re-entrant lip shape and the toroidal radius of the piston bowl on the high-speed direct-injection (HSDI) diesel engine. The results have shown that a large-toroidalradius bowl produces better combustion and hence better engine performance than a small-toroidalradius bowl does when a high injection pressure is used in an HSDI diesel engine. The larger toroidal radius is effective in lowering the brake specific fuel consumption (BSFC) and soot emission.

Genzale and Reitz [8] reported that the piston bowl diameter influences the in-cylinder mixing and pollutant formation processes by altering jet-jet and jet-wall interactions. When the fuel jets impinge on the bowl wall prior to ignition, adjacent jets merge, forming fuel-rich regions where soot formation occurs. By using a smaller-diameter bowl, a strong jetwall interaction pushes the fuel-rich jet-jet interaction regions into the centre of the chamber, where mixtures are predominantly lean. This reduces net soot formation and displaces fuel-lean regions of otherwise incomplete combustion into the combusting regions near the bowl wall.

Middlemiss [9] reported that reducing the throat diameter of the combustion chamber can enhance the squish flow and improve the fuel-air mixing, therefore reducing the particulate and specific fuel consumption but increasing the nitrogen oxide $\left(\mathrm{NO}_{x}\right)$ emission. It was also reported that the bowl with reduced throat diameter and retarded injection timing could reduce not only soot but also $\mathrm{NO}_{x}$ emission [10-12]. A sharp squish lip shape can reduce the smoke without increasing $\mathrm{NO}_{x}$ emission in a typical combustion chamber [9].

Nishida and co-workers [13-15] have investigated many group-hole nozzles with different included injection angles and compared them with singlehole nozzles. They showed that the included injection angle is an important parameter for spray formation. Nozzles with negative included angles were found to have a similar characteristic to that of a conventional nozzle. Diverging nozzles with a positive included angle between the sprays showed a tendency to reduce the penetration length while improving the atomization. The penetration length and atomization increase for cluster nozzles with higher injection pressures [16, 17]. Gao et al. [18] have performed engine visualization studies using 
parallel and diverging group-hole nozzles. They found higher pressure and heat release rates for the premixed combustion phase and lower flame luminosity for low-load conditions, indicating better atomization and mixing and lower overall soot levels. Zhang et al. [19] studied group-hole nozzles as an alternative solution to the problems associated with minimization of the orifice diameter. They conducted the experiments in a high-temperature high-pressure constant-volume vessel using a common-rail injection system. They concluded that the group-hole nozzle has better fuel atomization, fuel evaporation, and air entrainment without a decrease in the tip penetration with the same total crosssection area of injection.

In previous studies, the cluster nozzles were tested in a wide re-entrant combustion chamber and compared with the reference nozzle [20-23]. However, the original chamber is not considered optimal for clusters with shorter spray tip penetration. For this reason, a new bowl was designed by utilizing hints from the previous engine experiments, fundamental spray measurements [24-26], and numerical simulations [20, 27]. The newly designed combustion bowl is characterized by a smaller diameter and a deeper bowl. It is expected to improve fuel-air mixing by better spray guidance. The new bowl geometry with a smaller diameter requires an increase in the depth of the piston bowl and a lower central pip in order to keep the same bowl volume.

Four clusters were used to investigate the variation in the start-of-injection (SOI) timings for four different test points, and the results are compared with those for the reference nozzle. The cluster with the best results for smoke emissions in the first set of tests was also tested for three different swirl ratios and two different nozzle tip protrusion (NTP) lengths with the new bowl.

\section{EXPERIMENTAL SET-UP}

\subsection{Engine}

The experiments were performed on a 0.81 singlecylinder engine (16.8:1 compression ratio) with 1.5 swirl ratio based on a V-8 Duramax engine from General Motors. The specifications of the singlecylinder engine are given in Table 1 . The engine is equipped with a Bosch CRI-3.3 injection system for the cluster nozzles. A piezo injector was used to improve the combustion further. The more accurate control, faster response, and higher needle velocities of piezo injectors allow more precise control of
Table 1 The specifications of the Duramax singlecylinder engine

\begin{tabular}{lc}
\hline Engine & $\begin{array}{l}\text { Duramax single-cylinder } \\
\text { engine }\end{array}$ \\
\hline Displacement volume (l/cylinder) & 0.825 \\
Bore (mm) & 103 \\
Stroke (mm) & 99 \\
Connecting rod length (mm) & 188 \\
Piston-pin offset (mm) & 0.5 \\
Compressing ratio & $16.8: 1$ \\
Squish height (mm) & 0.7 \\
Swirl ratio & 1.5 \\
Maximum rail pressure (bar) & 2200 \\
Maximum pressure in cylinder (bar) & 160 \\
Maximum speed (1/min) & 3600 \\
\hline
\end{tabular}

injection duration. The injectors are controlled using a Genotec injection controller. A re-entrant combustion chamber with $59.8 \mathrm{~mm}$ throat diameter and $15.6 \mathrm{~mm}$ depth length was used for the measurement. A schematic diagram of the engine test cell is shown in Fig. 2. In order to keep the intake air conditions identical with those of the real production engine, a three-step compressor supplied the required boost pressure, while the air temperature at the engine intake was controlled by three intercoolers, keeping the desired inlet conditions in a surge tank of the intake pipe. The airflow rate was measured with a hot-wire flow meter. The exhaust back pressure produced by a throttle valve in the real engine was simulated by the valve placed in the exhaust system, controlling the pressure in the exhaust surge tank. An exhaust gas recirculation (EGR) valve allows control of the EGR rate. Dedicated conditioners are used to maintain the temperature and pressure of the coolant and oil.

\subsection{Bowl geometry}

The piston bowl for MY06 by General Motors and a new modified piston bowl were used for the experiments. Figure 3 shows sketches of both the bowl geometries. The new combustion chamber is designed to enhance air-fuel mixing in the diffusion combustion region for the clusters. The new combustion bowl is characterized by a smaller diameter and a deeper bowl. The volume of the new piston bowl is the same as that of the original bowl to keep the same compression ratio of 16.8. In fundamental spray measurements, the cluster with $10^{\circ}$ included angle was found to have spray tip penetration about $3 \mathrm{~mm}$ shorter than that of the reference nozzle under typical engine operating conditions, i.e. 800 bar rail pressure and $500 \mu$ s energizing time. Therefore a smaller bowl radius was chosen. The central pip is 


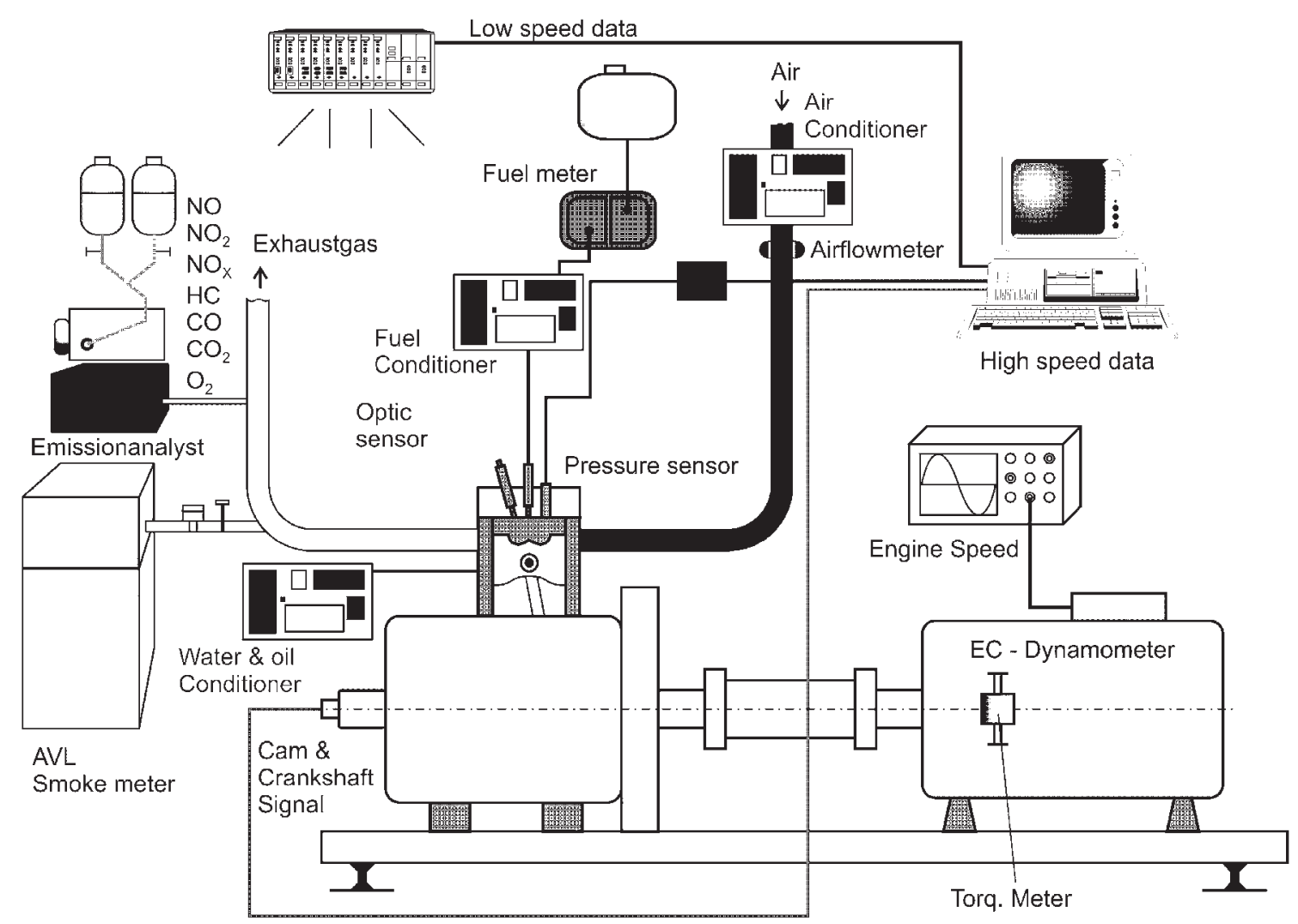

Fig. 2 Schematic diagram of the engine test cell

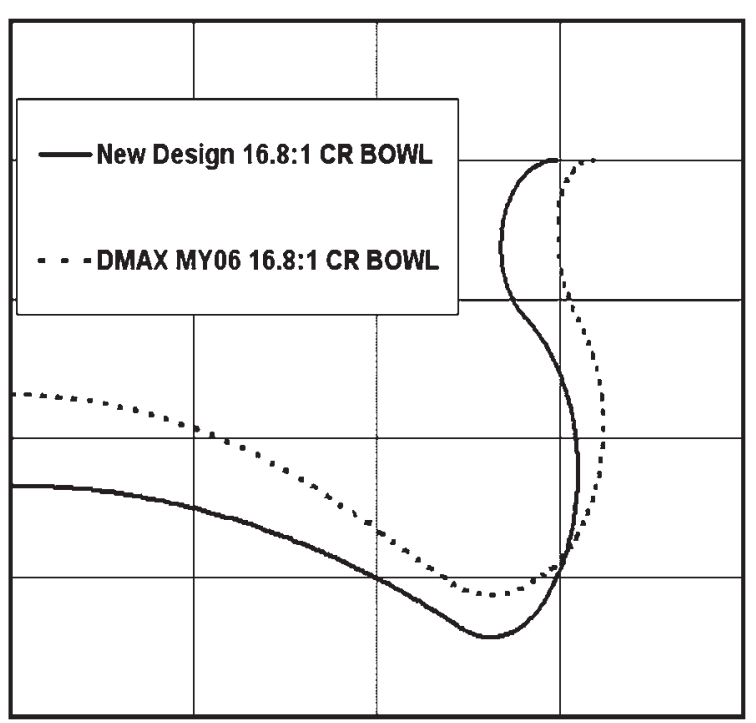

Fig. 3 Sketches for MY06 by General Motors and a new modified piston bowl (CR, compression ratio)

also designed to be deeper for the vertical clusters because the cluster with larger included angle increases the contact between the vapour phase and the bottom of the bowl wall. The toroidal radius is also increased to attain better air-fuel mixing for the clusters.

\subsection{Cluster nozzles}

A total of four clusters with different numbers of pairs of holes, each having a $10^{\circ}$ included angle, was designed for the current study. All the clusters had groups of two orifices with the same hole diameter, as it leads to reasonable orifice sizes. Table 2 lists the parameters for the reference nozzle and the clusters. Two different orientations for placement of the orifices were used. The clusters with one orifice circle (henceforth called horizontal) have both the orifices placed in a plane perpendicular to the injector axis, forming only one spray cone; the clusters with two orifice circles (henceforth called vertical) have the two orifices of a group placed along the injector axis, effectively forming two spray cones. Figure 4 shows sketches of the orifice orientations for the clusters. Two of the clusters have the vertical configuration and two have the horizontal configuration. The horizontal clusters were designed with the same spray-cone angles as the reference injector $\left(158^{\circ}\right)$ for better targeting, and the outer sprays of the vertical clusters were also targeted so that they had similar spray-cone angles to that of the reference injector $\left(158^{\circ}\right)$.

The clusters are named according to their geometry. The first part denotes the total number of orifices 
Table 2 Geometric specifications of the cluster nozzles and the reference nozzle

\begin{tabular}{|c|c|c|c|c|c|c|}
\hline $\begin{array}{l}\text { Number of hole pairs } \\
\text { (number of holes) }\end{array}$ & $\begin{array}{l}\text { Centre-line angle } \\
\beta \text { (deg) }\end{array}$ & $\begin{array}{l}\text { Flow number }\left(\mathrm{cm}^{3}\right. \\
\text { for } 30 \mathrm{~s} \text { at } 100 \mathrm{bar})\end{array}$ & $\begin{array}{l}\text { Included } \\
\text { angle } \alpha \text { (deg) }\end{array}$ & $\begin{array}{l}\text { Hole } \\
\text { separation } \\
(\mathrm{mm})\end{array}$ & $\begin{array}{l}\text { Cluster } \\
\text { configuration }\end{array}$ & Name \\
\hline $7(7)$ & 158 & 405 & - & - & - & $7 \times 158$ \\
\hline 7 (14) & 158 & 490 & 10 & 0.500 & Horizontal & $14 \times 158 / 158$ \\
\hline $5(10)$ & 158 & 490 & 10 & 0.600 & Horizontal & $10 \times 158 / 158$ \\
\hline 7 (14) & $148(158 / 138)$ & 490 & 10 & 0.600 & Vertical & $14 \times 158 / 138$ \\
\hline $5(10)$ & $148(158 / 138)$ & 430 & 10 & 0.600 & Vertical & $10 \times 158 / 138$ \\
\hline
\end{tabular}
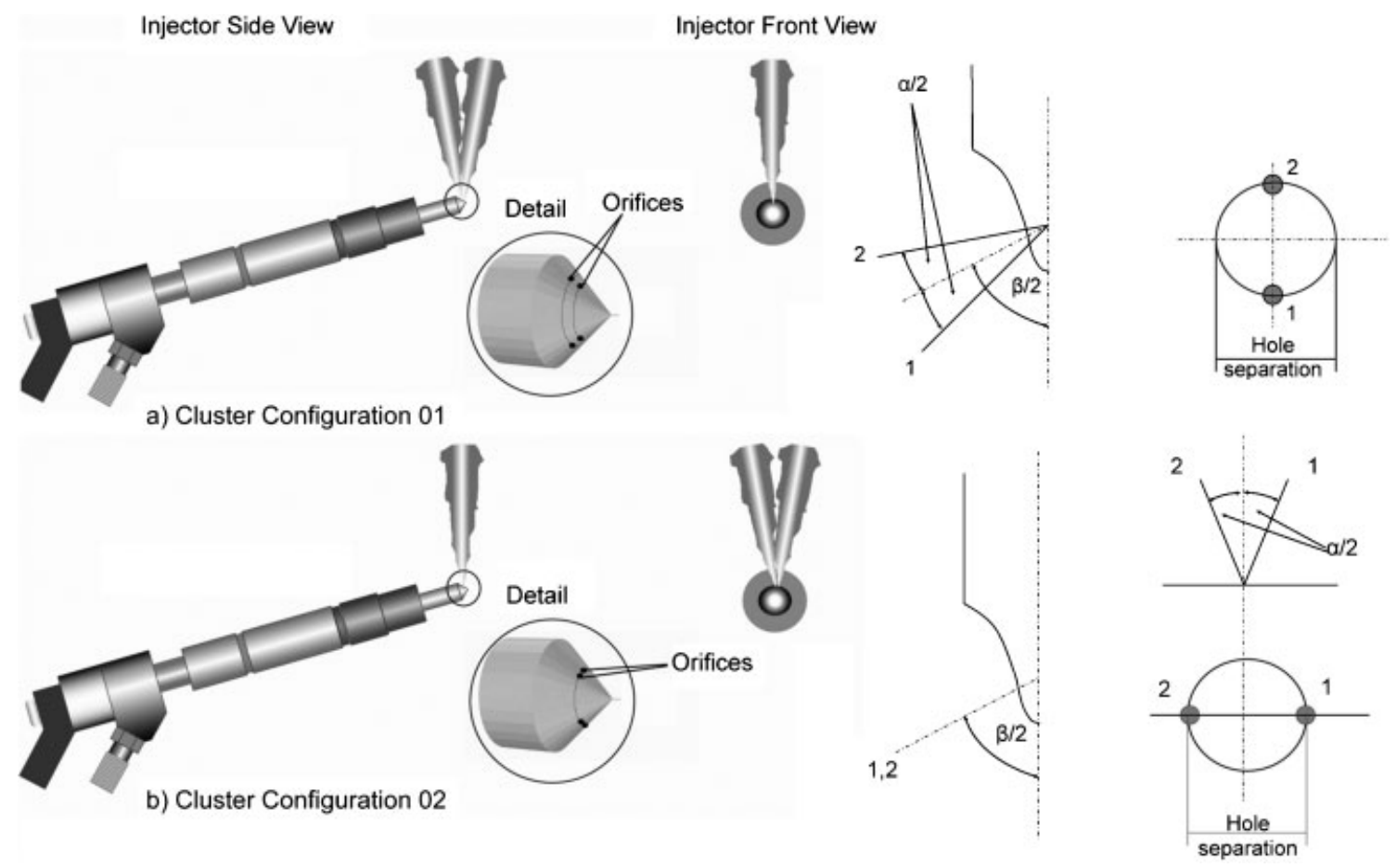

Fig. 4 Sketches of orifice orientations for (a) horizontal and (b) vertical clusters

(ten or 14). The two numbers separated by a solidus denote the spray cone angle formed by the orifices in different orifice circles (only one orifice circle for horizontal configuration). The reference nozzle has a flow number of 405 and was designed with a $0.131 \mathrm{~mm}$ orifice diameter. The seven-hole-pair clusters were designed with a $0.105 \mathrm{~mm}$ orifice diameter for a flow number of 490 . The flow number is defined as the amount of fuel in cubic centimetres which flows through the nozzle in $30 \mathrm{~s}$ at a pressure difference of 100 bar. The seven-hole-pair clusters were designed with a higher flow number to match the spray tip penetration with that of the reference nozzle. The other clusters with five hole pairs were designed for the same flow number $\left(490 \mathrm{~cm}^{3}\right.$ for $30 \mathrm{~s}$ at $100 \mathrm{bar}$ ). The clusters were designed with a $0.123 \mathrm{~mm}$ orifice diameter to keep the same flow number. However, cluster $10 \times 158 / 138$ has a slightly lower flow number than the other clusters.

\subsection{Test points}

The test points are described in Table 3 . The test points TP1 and TP2 represent low-load operation and high-load operation respectively under a low engine speed. TP3 and TP4 were used for mediumload operation and high-load operation respectively under a high engine speed. The test points in Table 3 were defined with their indicated mean effective pressures (IMEP) and the engine speeds, both of which were maintained constant for all the tests for a test point. The SOI and rail pressure were varied within the shown limits. The injection duration was varied to maintain the IMEP as specified in Table 3 , while specified levels of $\mathrm{NO}_{x}$ were achieved by varying the EGR. Injection rate measurements were carried out for all the nozzles to determine the actual injected mass for the test points.

For TP1, the clusters and reference nozzle were first tested for different injection pressures from 
Table 3 The test points

\begin{tabular}{|c|c|c|c|c|c|c|c|c|c|c|}
\hline $\begin{array}{l}\text { Test } \\
\text { point }\end{array}$ & $\begin{array}{l}\text { Engine } \\
\text { speed } \\
(\mathrm{r} / \mathrm{min})\end{array}$ & $\begin{array}{l}\text { Rail pressure } \\
\text { (bar) }\end{array}$ & $\begin{array}{l}\text { IMEP } \\
\text { (bar) }\end{array}$ & $\begin{array}{l}\text { SOI } \\
\text { (deg CA } \\
\text { ATDC) }\end{array}$ & $\begin{array}{l}\text { Boost } \\
\text { pressure } \\
\text { (bar) }\end{array}$ & $\begin{array}{l}\text { Boost } \\
\text { temperature } \\
\left({ }^{\circ} \mathrm{C}\right)\end{array}$ & $\begin{array}{l}\text { Temperature } \\
\text { of the oil and } \\
\text { coolant }\left({ }^{\circ} \mathrm{C}\right)\end{array}$ & $\begin{array}{l}\text { Air-to- } \\
\text { fuel ratio }\end{array}$ & EGR (\%) & $\begin{array}{l}\text { Emission index } \\
\text { of } \mathrm{NO}_{x}(\mathrm{~g} /(\mathrm{kg} \\
\text { of fuel }))\end{array}$ \\
\hline TP1 & 1400 & $500-900,600$ & 4.5 & $-5,-27$ & 1.13 & 55 & 90 & $23-29$ & $33-48$ & $0.5,2.0,4.0$ \\
\hline TP2 & 1400 & 1500 & 10.5 & -10 to 4 & 1.57 & 57 & 90 & $18-20$ & $23-33$ & 4.5 \\
\hline TP3 & 2800 & 1800 & 10.2 & -10 to 4 & 2.3 & 60 & 90 & $29-32$ & $25-35$ & 4.5 \\
\hline TP4 & 2800 & 2000 & 15.2 & -10 to 4 & 2.35 & 80 & 90 & $19-22$ & $18-25$ & 5.0 \\
\hline
\end{tabular}

500 bar to 900 bar for an SOI of $-5^{\circ}$ crank angle (CA) after top dead centre (ATDC) with an $\mathrm{NO}_{x}$ emission index of $4 \mathrm{~g} /(\mathrm{kg}$ of fuel). Then they were measured with 600 bar rail pressure at an SOI of $-27^{\circ}$ CA ATDC with varying EGR under premixed charge compression ignition (PCCI) conditions for TP1. For TP2, TP3, and TP4, tests with SOI variations were carried out with rail pressures of $1500 \mathrm{bar}, 1800 \mathrm{bar}$, and 2000 bar respectively. The SOI was varied between $-10^{\circ}$ and $+4^{\circ}$ CA ATDC in $2^{\circ}$ steps.

\section{RESULTS AND DISCUSSION}

\subsection{The comparison between the original bowl and the new bowl}

Increasing the strength of the impingement (by reducing the bowl diameter) helps to transport rich polycyclic aromatic hydrocarbon (HC)-soot formation regions towards the centre of the combustion chamber where lean equivalence ratios exist, possibly leading to a decrease in soot formation and/or an increase in soot oxidation. The injection rates for cluster $14 \times 158 / 158$ and the reference nozzle were measured with $460 \mu$ s and $480 \mu$ s energizing times for 1800 bar injection pressure and are shown in Fig. 5. The cluster with a high flow number has a higher injection rate than the reference nozzle. In this

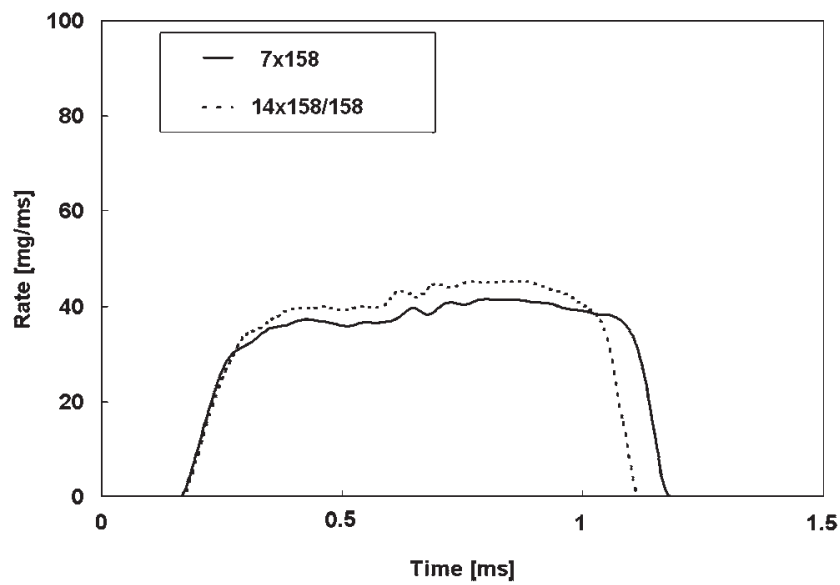

Fig. 5 Injection rates for cluster $14 \times 158 / 158$ and the reference nozzle condition, injected fuel was $43.15 \mathrm{mg} /$ injection for cluster $14 \times 158 / 158$, and $44.31 \mathrm{mg} /$ injection for the reference nozzle. Injection rate measurements were also carried out for the nozzles employing the injection durations used in the engine experiments to determine the actual injected mass for the engine measurement.

\subsubsection{Rail-pressure variation}

Figure 6 shows smoke emissions for different rail pressures and the two bowl geometries at the SOI of $-5^{\circ}$ CA ATDC for TP1. With both bowls, the clusters show extremely high smoke levels for lower rail pressures under conventional injection timing, but

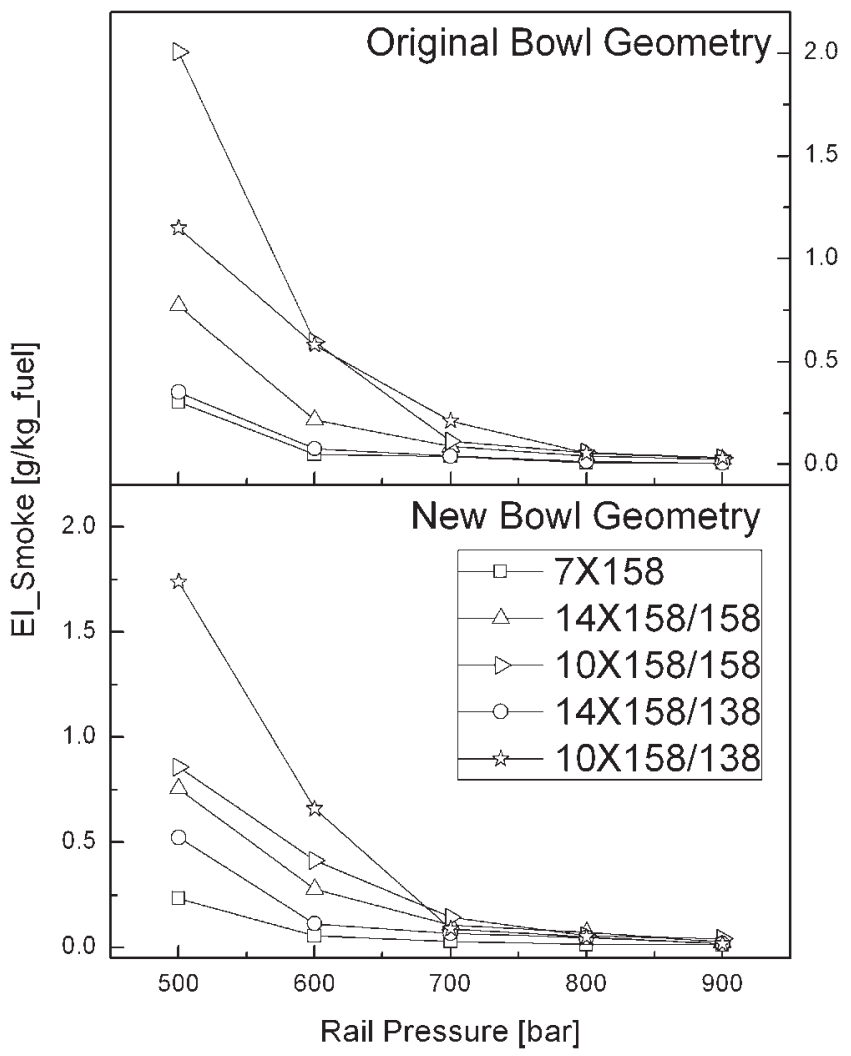

Fig. 6 Emission index of smoke (EI_Smoke) with different rail pressures for TP1 $(1400 \mathrm{r} / \mathrm{min}$; 4.5 bar IMEP; $4 \mathrm{~g} /\left(\mathrm{kg}\right.$ of fuel $\mathrm{NO}_{x}$ ) at an SOI of $-5^{\circ}$ CA ATDC) 
the smoke emissions were reduced to levels similar to that of the reference nozzle by increasing the rail pressure. Among the compared clusters, the sevenhole-pair clusters with relatively smaller orifices show lower smoke emissions than do the five-holepair clusters. The results for the original bowl are compared with those for the new bowl. There is no strong effect of the bowl geometry for TP1 and the results are very similar for both the bowl geometries. In this operating condition, only a small mass of fuel is injected in the chamber, and so the spray-spray interactions are more important than the spray-wall interactions.

\subsubsection{Premixed charge compression ignition}

PCCI is one of the advanced strategies to reduce smoke and $\mathrm{NO}_{x}$ emissions simultaneously under the part-load condition. The fuel is injected at a very early timing with a large amount of cooled EGR to increase the ignition delay. This lowers the combustion temperature. The results are discussed for an early injection timing of $-27^{\circ}$ CA ATDC with 600 bar rail pressure for different $\mathrm{NO}_{x}$ emission levels for TP1. The results for fuel consumption and HCs for the same conditions are shown in Figs 7 and 8 respectively. The BSFC of the clusters is generally lower than that of the reference nozzle for both the piston bowl geometries. The clusters are regarded as a promising approach to lower fuel consumption at early injection timing because the sprays from clusters have a greater mass of entrained ambient gas and greater mass of fuel vapour than the reference nozzle $[\mathbf{1 6}, \mathbf{1 8}]$. In the PCCI condition, $\mathrm{HC}$ and carbon monoxide (CO) emissions are of major concern, because $\mathrm{HC}$ and $\mathrm{CO}$ emissions are usually higher with lower combustion temperatures. The clusters show an improvement for HCs, because the reference nozzle with a longer spray tip penetration causes more fuel to be delivered in the proximity of the cylinder liner and combustion chamber walls, where flame quenching occurs. The trends are the same for the new bowl. The clusters have shown lower HC levels than the reference nozzle. Comparing the two bowl geometries, all the nozzles have higher HC levels with the new bowl. The new bowl has a smaller diameter and so the spray can reach the low-temperature quenching areas more rapidly; thus more fuel reaches close to the combustion chamber walls.

The results of smoke emissions are shown in Fig. 9. Except for cluster $10 \times 158 / 158$ which was designed with a relatively larger orifice diameter, all

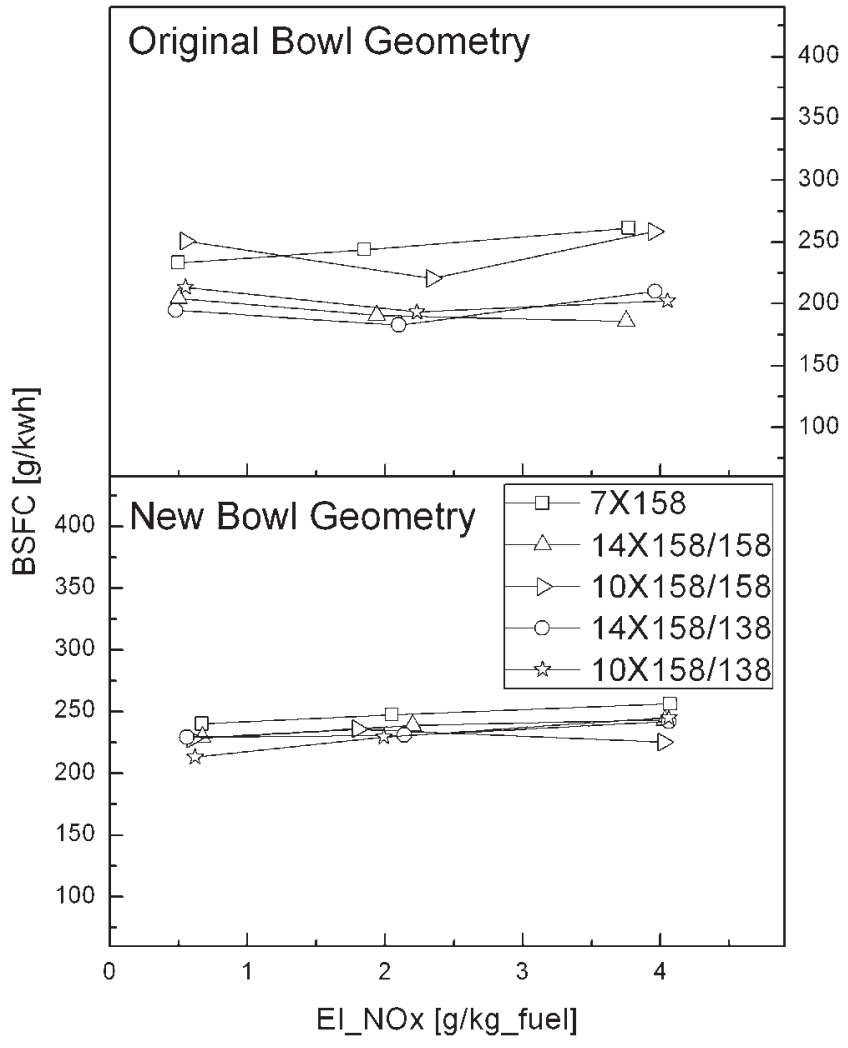

Fig. 7 BSFC versus the emission index of $\mathrm{NO}_{x}$ (EI_$\mathrm{NO}_{x}$ ) for TP1 (1400 r/min; 600 bar rail pressure; 4.5 bar IMEP at an SOI of $-27^{\circ}$ CA ATDC)

the clusters show lower smoke levels than the reference nozzle. The clusters were designed with different orifice diameters to keep the same flow number, except for cluster $10 \times 158 / 138$, which had a smaller flow number than the others. The results for smoke emissions are similar for both the bowl geometries for all the nozzles except the reference nozzle and cluster $10 \times 158 / 158$. The fact that the reference nozzle and cluster $10 \times 158 / 158$ have relatively longer spray tip penetration causes a strong increase in the smoke levels with the new bowl. The seven-hole-pair clusters show lower smoke emission than other nozzles do. The increase in spray-wall interaction with the reduction in the bowl diameter could be the reason behind these observations.

\subsubsection{Low-engine-speed high-load condition (TP2)}

The clusters were investigated in two chambers with different bowl geometries for different SOIs under the high-load condition, and the results were compared with those of the reference nozzle. The injection timing under a high load is limited by intense diesel knock. For this reason, the injection 


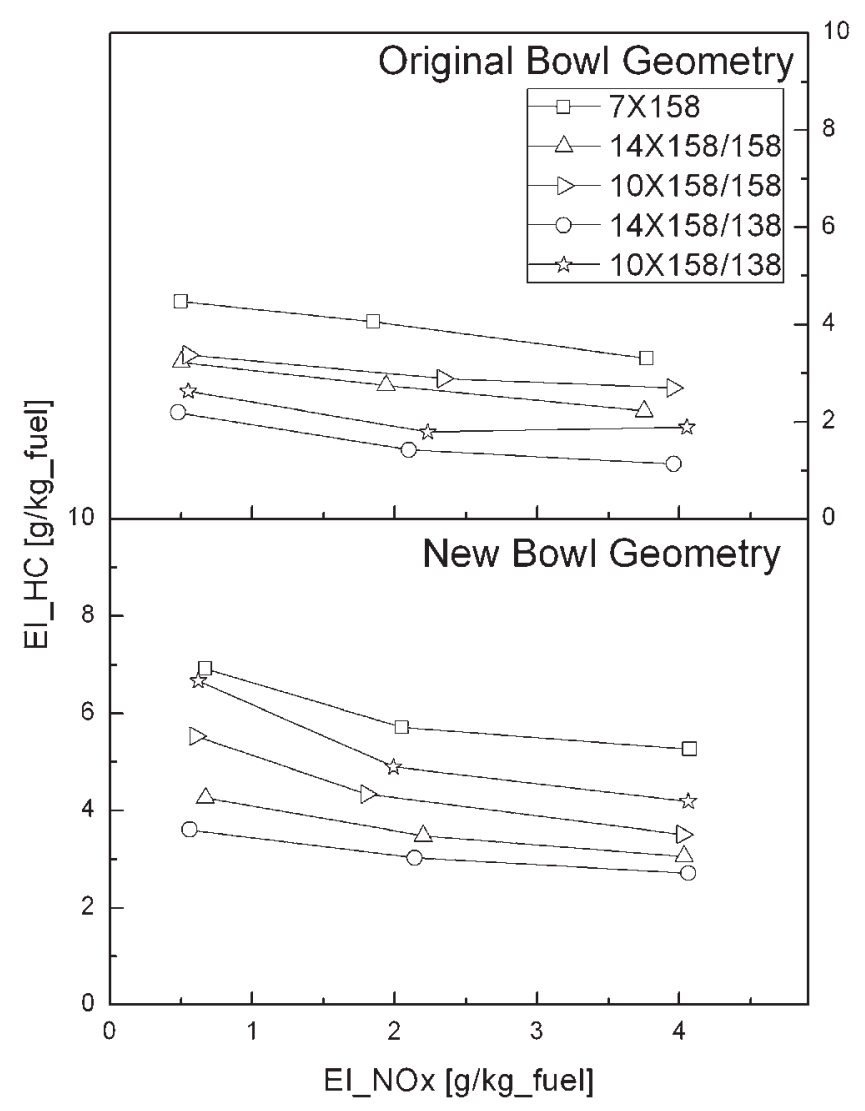

Fig. 8 Emission index of HC (EI_HC) versus the emission index of $\mathrm{NO}_{x}\left(\mathrm{EI}_{-} \mathrm{NO}_{x}\right)$ for TP1 (1400 r/min; 600 bar rail pressure; 4.5 bar IMEP at an SOI of $-27^{\circ} \mathrm{CA}$ ATDC)

timings were varied between $-10^{\circ} \mathrm{CA}$ ATDC and $4^{\circ}$ CA ATDC. The main purpose of this study is to find a solution to the problem of high smoke levels under the high-load condition. The size of the orifices, spray targeting, and spray tip penetration should be important parameters for TP2 because a large amount of fuel was injected in this condition while the engine speed was relatively lower; the spray tip penetrations were long enough to see the effect of spray targeting. The clusters were investigated in a conventional wide piston bowl and a new piston bowl with reduced diameter.

The results of BSFC and HC using five- and sevenhole-pairs clusters are shown in Figs 10 and 11 respectively. The clusters have better fuel consumption in both of the bowls than the reference nozzle. Under the high-load condition, the HC emissions are generally low for a diesel engine. The clusters have relatively lower HC emissions than the reference nozzle does in both the bowls for TP2. The difference between the HC emissions of the clusters and the reference nozzle in the new bowl is higher than the difference in the original bowl.

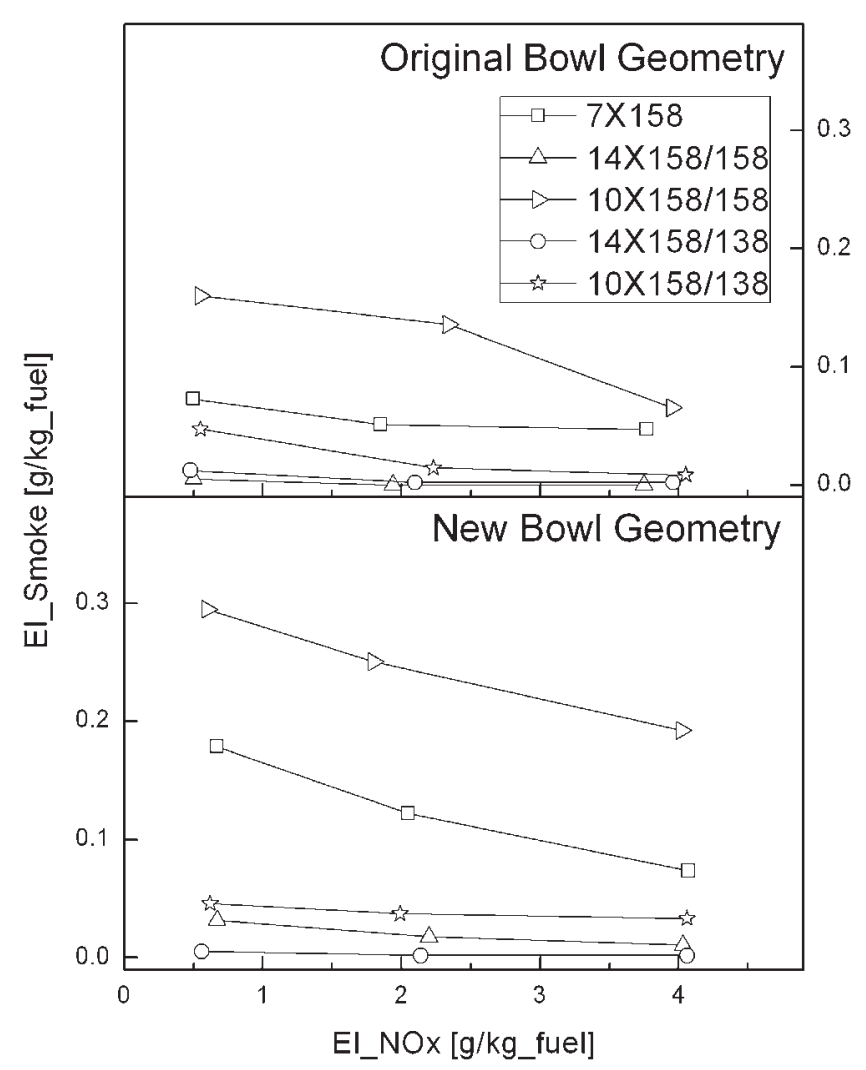

Fig. 9 Emission index of smoke (EI_Smoke) versus the emission index of $\mathrm{NO}_{x}\left(\mathrm{EI}_{-} \mathrm{NO}_{x}\right)$ for TP1 $(1400 \mathrm{r} / \mathrm{min}$; $600 \mathrm{bar}$ rail pressure; 4.5 bar IMEP at SOI $-27^{\circ} \mathrm{CA}$ ATDC)

The results of smoke emissions for five- and seven-hole-pair clusters are shown in Fig. 12. Cluster $14 \times 158 / 158$ shows lower smoke levels than the reference nozzle, while the other clusters show higher smoke emissions than the reference nozzle. Comparing the cluster configurations, the vertical clusters have relatively higher smoke emissions than the horizontal clusters and the reference nozzle, in both the bowl geometries. The horizontal clusters, which were designed with a $158^{\circ}$ spray cone angle, the same as the reference nozzle, have better spray targeting and mixture formation near the piston bowl [20]. The spray of horizontal clusters is injected towards the top part of the piston bowl from where it is guided along the bowl surface towards the centre of the bowl. In this way, sufficient air can be entrained during the mixing and combustion process, and thus the burning rate is accelerated. However, the vertical clusters show a higher smoke level. It seems that the two sprays, one directed towards the top part of the bowl and the other towards the middle or the bottom part of the bowl, guided against each other by the bowl contour, merge with each other and make a rich zone near the 


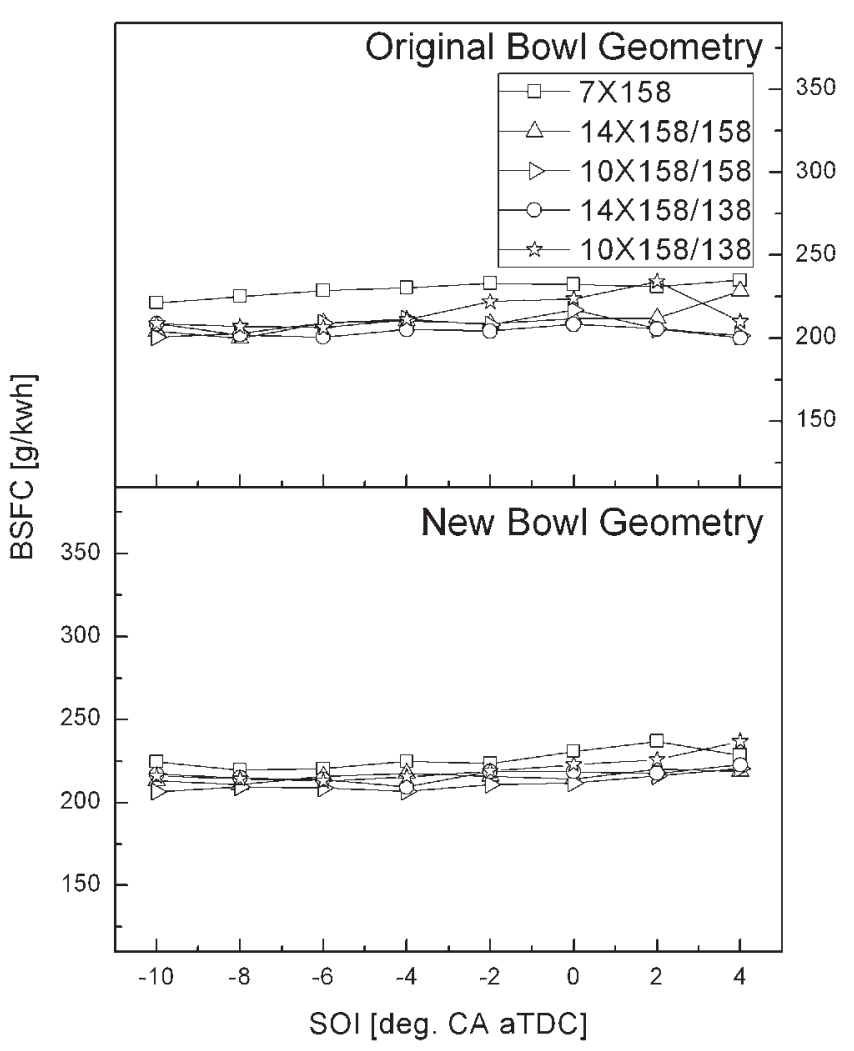

Fig. 10 BSFC versus SOI for TP2 (1400 r/min; $1500 \mathrm{bar}$ rail pressure; $10.5 \mathrm{bar}$ IMEP; $4.5 \mathrm{~g} /(\mathrm{kg}$ of fuel $\left.\mathrm{NO}_{x}\right)$ )

piston wall. This might be a source of higher smoke emissions for the vertical clusters.

Cluster $14 \times 158 / 158$ shows almost the same smoke levels for both the bowls, while the other nozzles show higher smoke levels for the new bowl geometry. It is expected that, as the new bowl has a smaller diameter, it should be less suitable for the five-holepair clusters and the reference nozzle as they have longer spray penetration lengths than the sevenhole-pair clusters do. The increase in smoke emissions for the seven-hole-pair vertical cluster is more apparent for the two extreme SOI points, while the change for intermediate SOI points is not as prominent as for the five-hole-pair clusters or the reference nozzle.

\subsubsection{High-engine-speed medium-load condition (TP3) and high-engine-speed full-load condition (TP4)}

The clusters were investigated under medium- and full-load conditions at a high engine speed. The sizes of the orifices and the spray targeting should be the determining factors for TP3 and TP4, because the spray tip penetration is smaller and the ignition

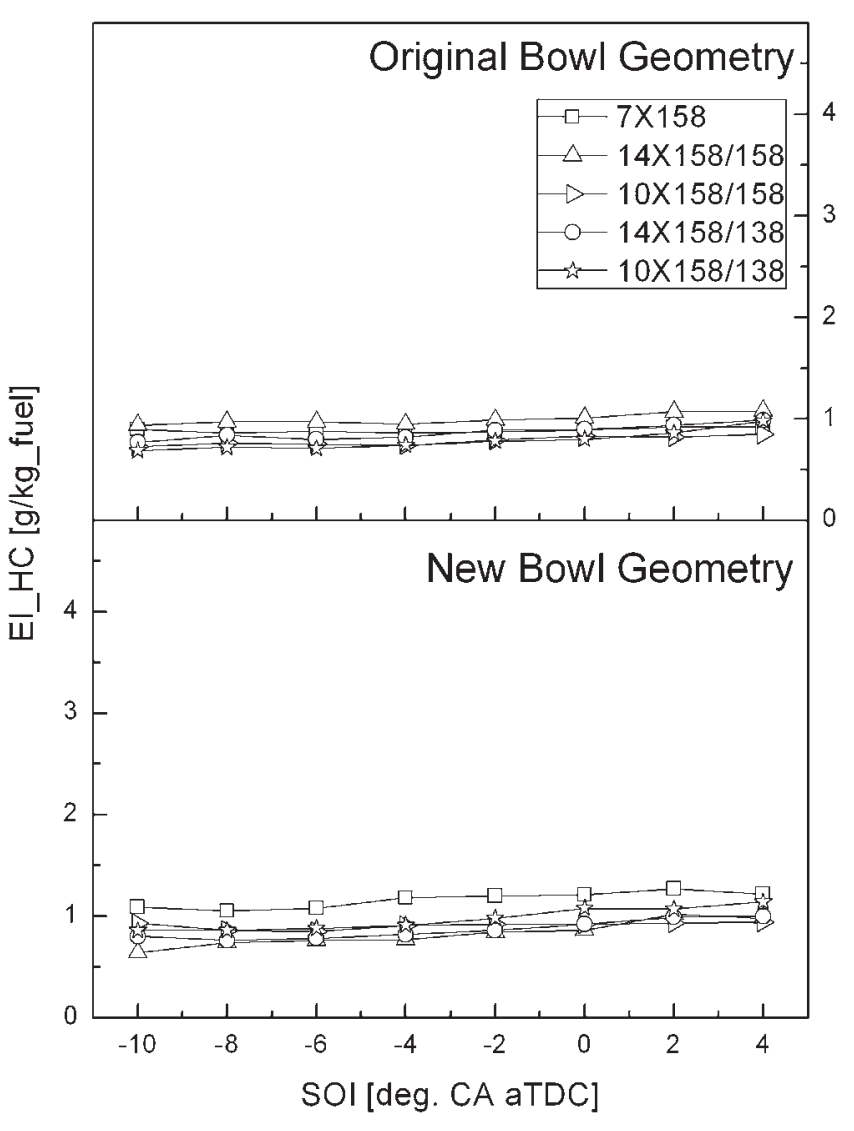

Fig. 11 Emission index of HC (EI_HC) versus SOI for TP2 (1400 r/min; 1500 bar rail pressure; 10.5 bar IMEP; $4.5 \mathrm{~g} /\left(\mathrm{kg}\right.$ of fuel $\left.\left.\mathrm{NO}_{x}\right)\right)$

delay is shorter than for the low-load conditions, owing to the higher boost pressure and temperature. Only the smoke emissions were compared for the medium- and full-load conditions because the HC and CO emissions are not major concerns for these operating conditions and were found to be within acceptable ranges for all the nozzles. The trends for the BSFC were very similar to those for TP2; therefore they are not shown for TP3 and TP4. The results for smoke emissions using five- and sevenhole-pair clusters for TP3 and TP4 are shown in Figs 13 and 14 respectively. Only one horizontal cluster (cluster $14 \times 158 / 158 \_10^{\circ}$ ) has shown smoke levels similar to those of the reference nozzle. All the other clusters have shown higher smoke levels than those of the reference nozzle for TP3 and TP4. All the seven-hole-pair clusters have relatively lower smoke emissions than the other clusters, and the horizontal clusters also have relatively lower smoke emissions than the corresponding vertical clusters for TP4. The clusters have shown an improvement in the smoke emissions with the new bowl. As is well known, correct targeting is an important parameter for the air-fuel mixing in a smaller-diameter chamber such 


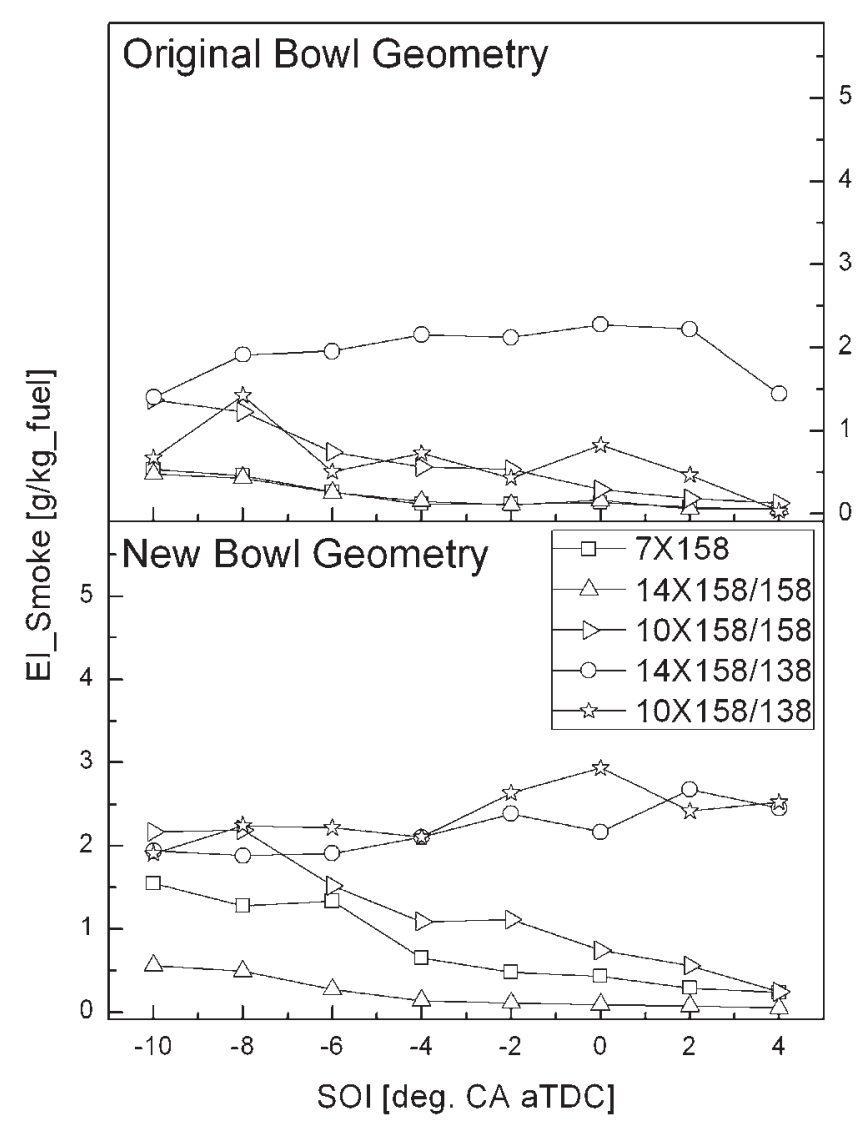

Fig. 12 Emission index of smoke (EI_Smoke) versus SOI for TP2 (1400 r/min; 1500 bar rail pressure; 10.5 bar IMEP; $4.5 \mathrm{~g} /\left(\mathrm{kg}\right.$ of fuel $\left.\mathrm{NO}_{x}\right)$ )

as a re-entrant bowl type. It strongly depends on the engine speed, injection system, and combustion chamber diameter. The new bowl design considers the shorter spray tip penetration of the clusters. The clusters with a small orifice have improved emissions using a high injection pressure, as better fuel atomization and evaporation are achieved. The new piston bowl with a smaller throat diameter and a larger toroidal radius helps to redirect the spray along the bowl wall back towards the centre of the bowl.

\subsection{Parametric study of the selected cluster nozzle}

As the final part of the study, cluster $14 \times 158 / 158$ was selected for a parametric study. It was chosen because it showed the best results for smoke emissions in the first set of tests. The cluster was investigated to find the effects of swirl and spray targeting on engine operation with the new bowl design. The mixing process in diesel engines is significantly affected by the bulk flow and the spray

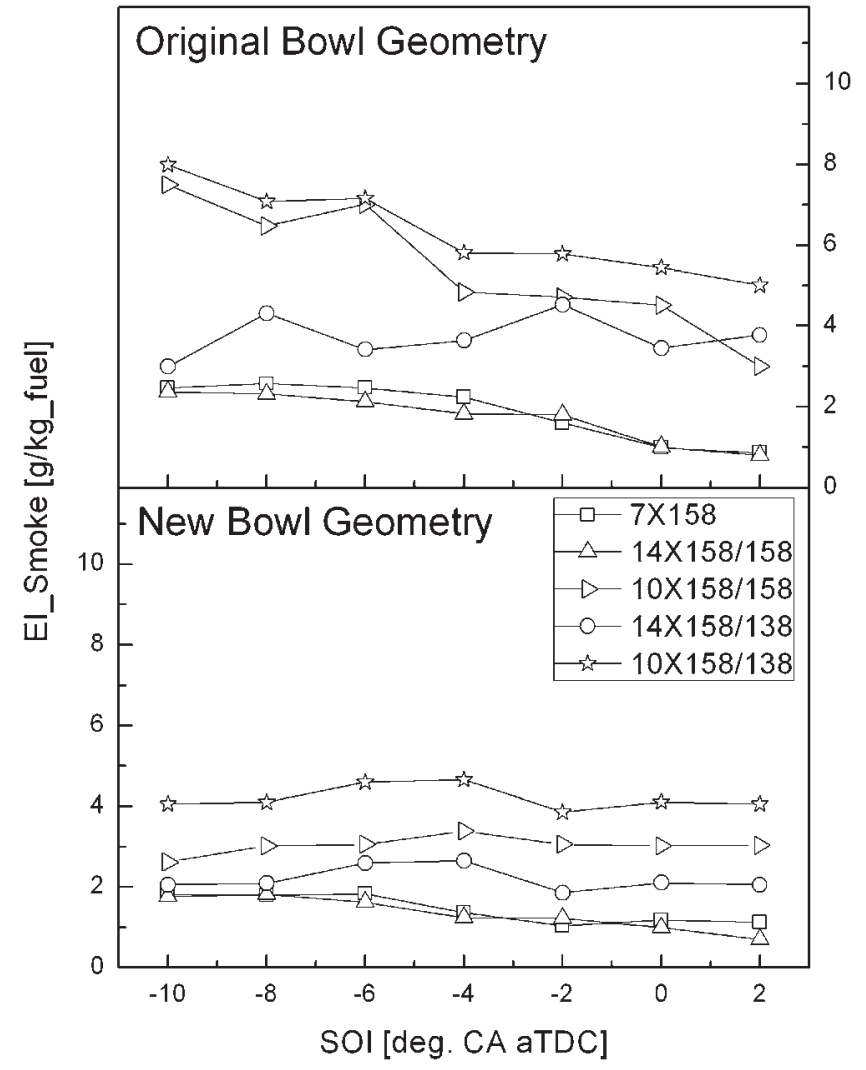

Fig. 13 Emission index of smoke (EI_Smoke) versus SOI for five- and seven-hole-pair clusters for TP3 (2800 r/min; 1800 bar rail pressure; 10.2 bar IMEP; $4.5 \mathrm{~g} /\left(\mathrm{kg}\right.$ of fuel $\left.\left.\mathrm{NO}_{x}\right)\right)$

targeting in the combustion chamber. Therefore it is necessary to match the bowl geometry with optimal initial flow motions such as swirl and proper spray targeting. The cylinder head has two helical intake ports, which are a high-swirl port and a low-swirl port. The swirl ratio was varied by partially blocking one of the intake ports using specially designed gaskets. In order to obtain a lower swirl ratio, a gasket was installed to keep the direct port completely open, while partially blocking the swirl port. The original gasket was used for the designed swirl ratio by keeping both the ports completely open. A higher swirl ratio was obtained by using the other gasket to partially block the direct port, while keeping the swirl port completely open. The cluster was measured for three different swirl ratios (mean swirl ratios (MSRs) of 0.5, 1.5, and 3.0) and two different NTP lengths $(1.65 \mathrm{~mm}$ and $2.5 \mathrm{~mm})$ with the new bowl. The protrusion length was changed by the thickness of the shim located between the injector and the cylinder head. The main purpose of the cluster concept is to reduce smoke emissions under the high-load condition while keeping the fuel consumption at a low level by improved atomization 


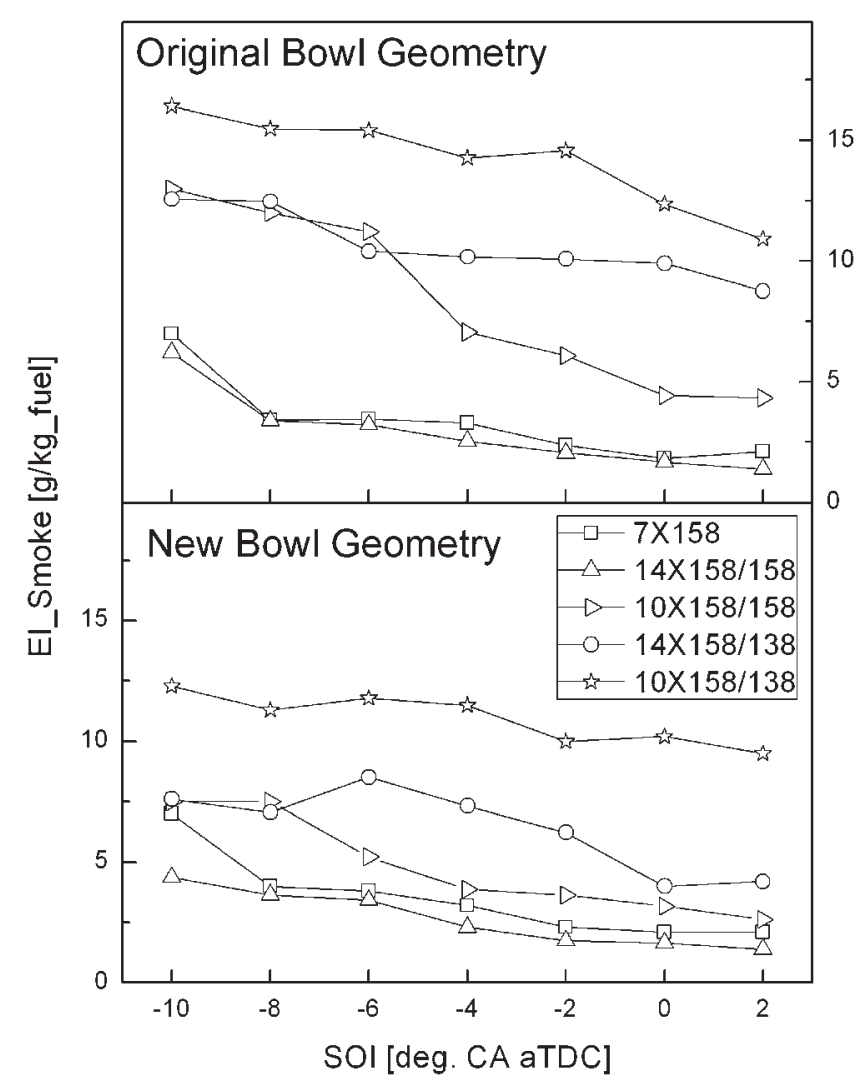

Fig. 14 Emission index of smoke (EI_Smoke) versus SOI for five- and seven-hole-pair clusters for TP4 (2800 r/min; 2000 bar rail pressure; 15.2 bar IMEP; $5 \mathrm{~g} /\left(\mathrm{kg}\right.$ of fuel $\left.\left.\mathrm{NO}_{x}\right)\right)$

and evaporation of fuel. The cluster was investigated for conventional injection timings for TP2, TP3, and TP4 and the results were compared with the results of the reference nozzle with the original bowl. Table 4 shows the parameters of the experiments.

\subsubsection{Pressure and heat release rate}

Figure 15 shows the pressures and heat release rates of cluster $14 \times 158 / 158$ and the reference nozzle for the bowls for TP1. The ignition delay in the case of the cluster is shorter than in the case of the reference nozzle with both the bowls. Also the combustion periods of the cluster were shorter than those of the reference nozzle with both the bowls. The initial rate of heat release is higher for both the nozzles with the modified bowl. Figure 16 shows the pressures and heat release rates for TP2. The heat release rates for clusters with higher hydraulic flow are higher during the premixed combustion and lower during the mixing-controlled combustion. The ignition delay is shorter while the heat release rates are higher during premixed combustion with the new bowl. It seems that the nozzles have improved evaporation in better fuel-air mixing, resulting in heat transfer and the spatial distribution of temperatures with the new bowl. The oscillations visible in the heat release rates for measurements with the new bowl are due to filtering artefacts.

\subsubsection{Emissions and fuel consumption}

The results of BSFC using the cluster and the reference nozzle are shown for variation in the SOI for TP2, TP3, and TP4 in Fig. 17. The BSFC for the cluster is lower than for the reference nozzle for all injection timings and test points. The new bowl should improve the fuel consumption for the cluster with better spray-wall interaction under these conditions. Swirl also helps to improve the fuel consumption for medium and high loads, and so case 04 with the highest swirl has the lowest BSFC for all test points. The HC emissions are generally low under the high-load condition. Most of the HC emissions form in flame-quenching regions with low temperatures. Under the high-load condition, the temperature in the cylinder and the temperature of combustion are relatively high, owing to the greater mass of fuel and the higher boost pressure and temperature. The HC emissions are shown in Fig. 18. They are quite similar and low for all the cases.

The results of smoke emissions for all the cases for TP2, TP3, and TP4 are shown in Fig. 19. As shown in the previous sections, cluster $14 \times 158 / 158$ generally has slightly lower smoke emissions than the reference nozzle does for case 01 (same conditions as the reference case). In case 02 the cluster was tested

Table 4 Geometric specifications of the cluster nozzles and the reference nozzle

\begin{tabular}{lllll}
\hline Case & Nozzle & Piston bowl & MSR & NTP $(\mathrm{mm})$ \\
\hline Reference & $7 \times 158$ & Original bowl & 1.5 & 1.65 \\
Case 01 & $14 \times 158 / 158$ & Original bowl & 1.5 & 1.65 \\
Case 02 & $14 \times 158 / 158$ & New bowl & 1.5 & 1.65 \\
Case 03 & $14 \times 158 / 158$ & New bowl & 0.5 & 1.65 \\
Case 04 & $14 \times 158 / 158$ & New bowl & 3.0 & 1.65 \\
Case 05 & $14 \times 158 / 158$ & New bowl & 1.5 & 2.50 \\
\hline
\end{tabular}




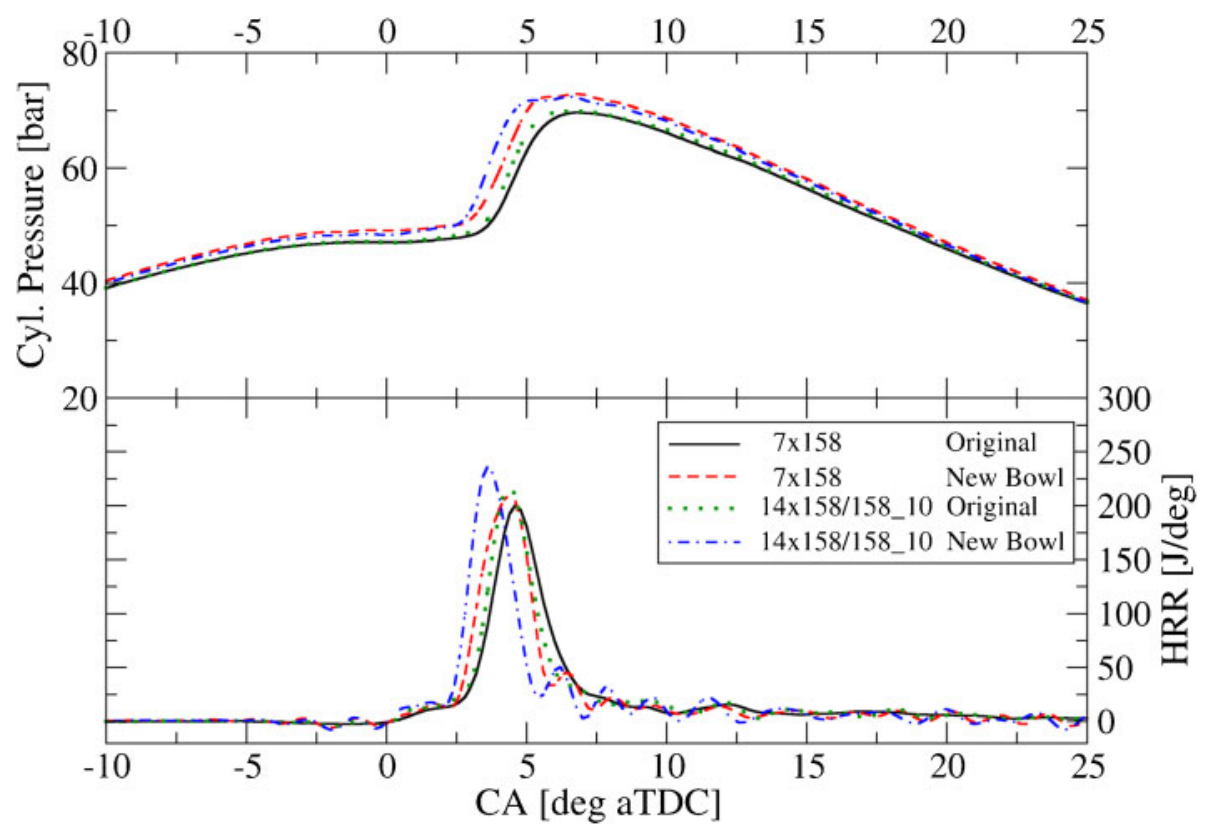

Fig. 15 Pressure and heat release rate (HRR) versus CA with the two bowls for cluster $14 \times 158$ / 158 and the reference nozzle for TP1 (1400 r/min; 900 bar rail pressure; 4.5 bar IMEP; $4.0 \mathrm{~g} /\left(\mathrm{kg}\right.$ of fuel $\left.\left.\mathrm{NO}_{x}\right)\right)$

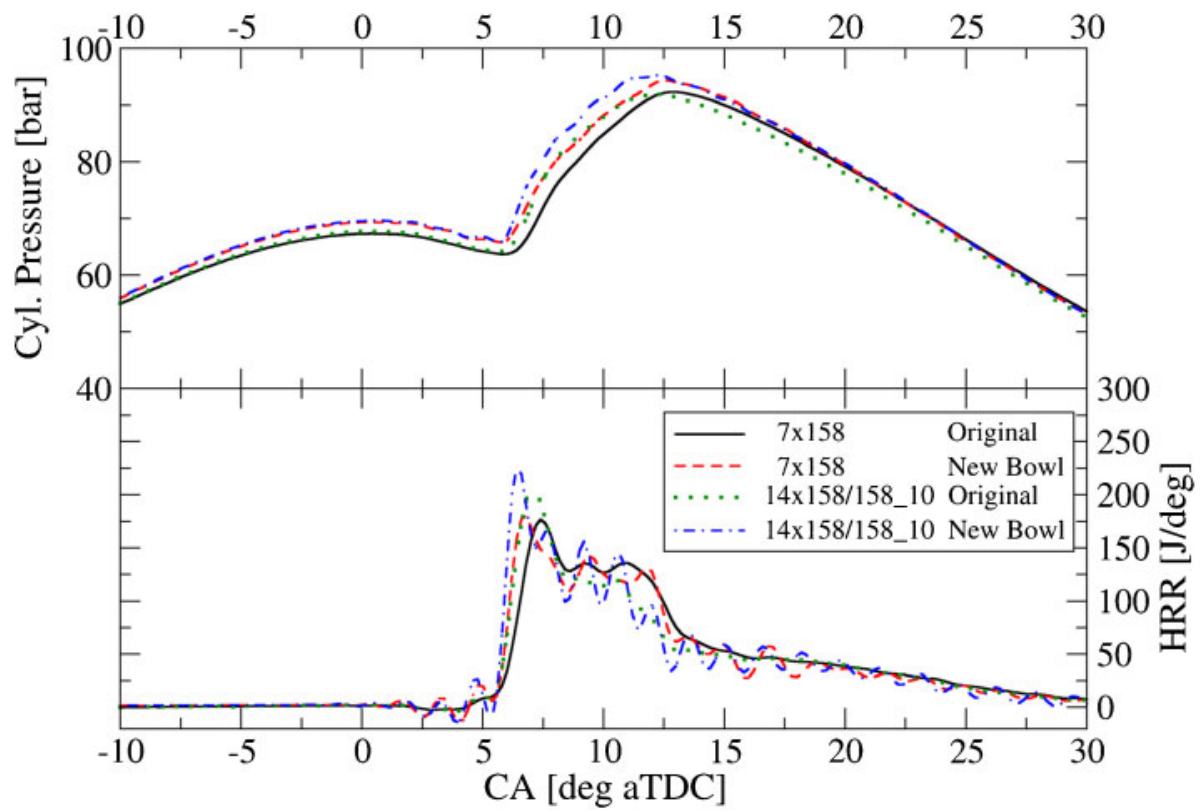

Fig. 16 Pressure and heat release rate (HRR) versus CA with the two bowls for cluster $14 \times 158$ / 158 and the reference nozzle for TP2 (1400 r/min; 1500 bar rail pressure; 10.5 bar IMEP; $4.5 \mathrm{~g} /\left(\mathrm{kg}\right.$ of fuel $\left.\left.\mathrm{NO}_{x}\right)\right)$

with the same conditions (swirl and shim) for the new bowl. The reductions in smoke emissions are stronger in this case than in case 01 . Case 02 has the lowest smoke emissions of all the test points. By using a smaller-diameter bowl, a strong jet-wall interaction pushes the fuel-rich spray-spray interaction regions into the centre of the chamber, where mixtures are predominantly lean $[\mathbf{7}, \mathbf{8}, \mathbf{2 8}]$. The smoke level is reduced by the spray motion near the piston bowl. The large-toroidal-radius bowl produces better combustion and hence better engine performance than the small-toroidal-radius bowl under the high-load condition with a high injection pressure [7]. The new bowl with smaller diameter 


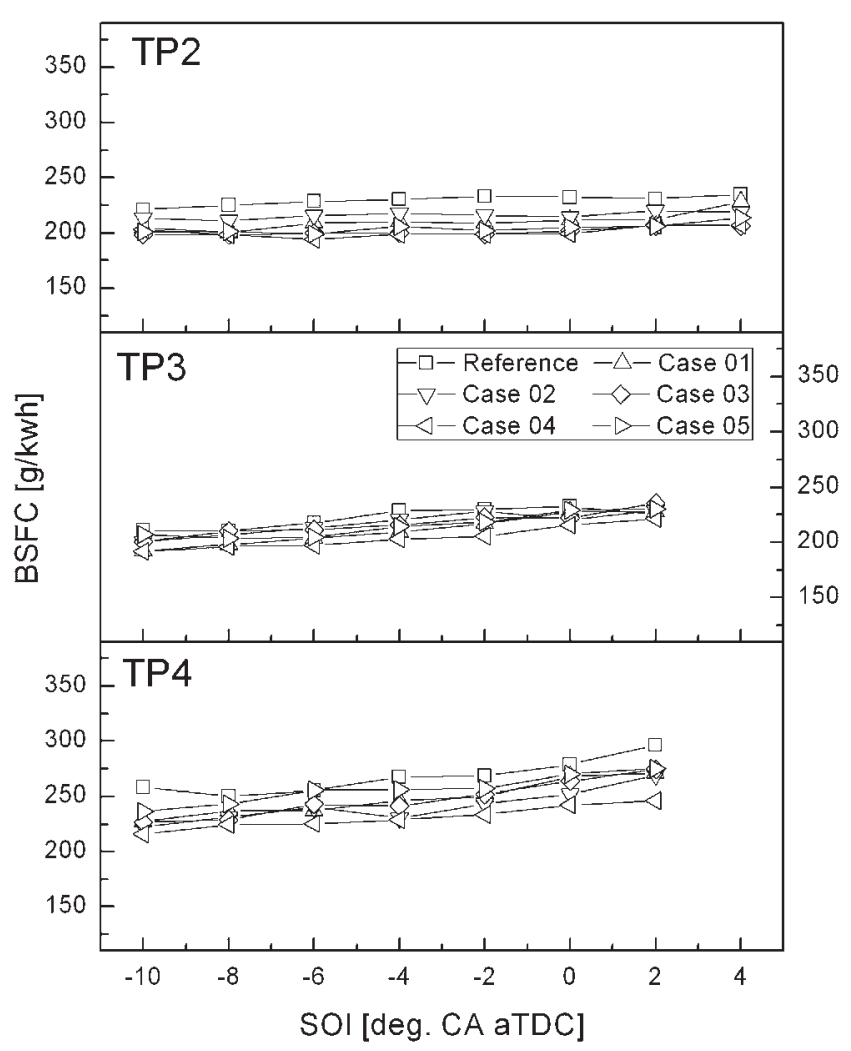

Fig. 17 BSFC versus SOI for cluster $14 \times 158 / 158$ compared with the reference nozzle for TP2, TP3, and TP4

and larger toroidal radius improves the fuel-air mixing. By comparing the results for cases 03 and 04 (variation in the swirl ratio), it is evident that the smoke emissions for the cluster increase with a higher or lower swirl than the original. Based on the results for smoke emissions in a previous study, an MSR of 1.5 seems to be close to the optimal swirl level for the cluster nozzles and the reference nozzle for the original bowl [29]. Since cases 03 and 04 have relatively higher smoke emissions than the reference nozzle does for most cases, it also seems that the MSR of 1.5 is close to optimal for the new bowl geometry. In an effort to understand the effect of spray targeting on the engine performance, case 05 was tested by changing the NTP. The orifices of the cluster were located at a deeper position (NTP of $2.5 \mathrm{~mm}$ instead of $1.65 \mathrm{~mm}$ ) in the cylinder with a thinner shim $(2.15 \mathrm{~mm})$ than the original $(3 \mathrm{~mm})$. The injected fuel spray is targeted more towards the centre of the bowl wall with a thinner shim. The smoke emissions increase significantly in case 05 and are higher than in the other cases. This also suggests that fuel-air mixing near the bowl wall has an influence on the overall fuel-air mixing process. The spray targeting is considered to be one of the

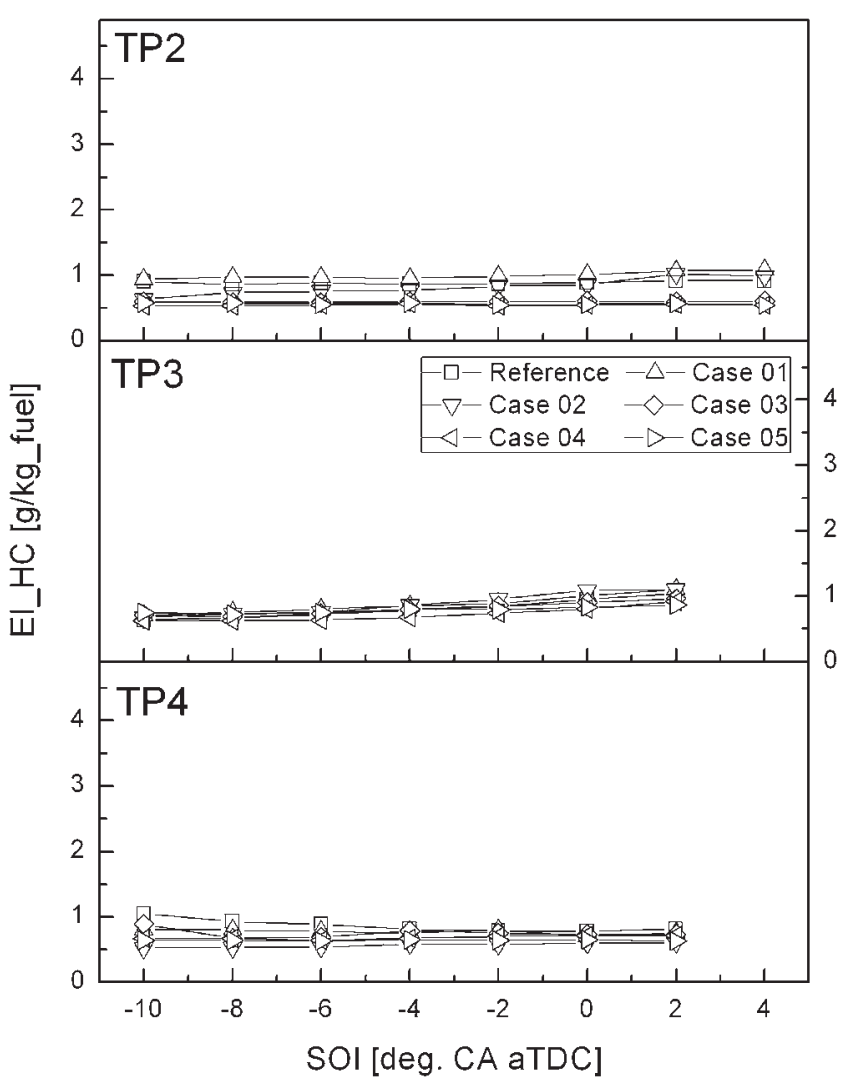

Fig. 18 Emission index of HC (EI_HC) versus SOI for cluster $14 \times 158 / 158$ compared with the reference nozzle for TP2, TP3, and TP4

important factors in fuel-air mixture formation for the spray motion near combustion bowl surface. Case 02 shows the lowest smoke emissions of all the cases.

\subsubsection{Reduction in smoke emissions by using the cluster nozzle}

As seen from the results of the parametric study, cluster $14 \times 158 / 158$ combined with a swirl level of $1.5 \mathrm{MSR}, 3 \mathrm{~mm}$ shim, and the new bowl reduces smoke emissions for all test points. Figure 20 shows the lowest levels of smoke emissions for each of the test points for the cluster (case 02) and the reference nozzle (reference case). The smoke emissions for low-engine-speed conditions (TP1 and TP2), which were already low with the reference nozzle, were further reduced by the cluster nozzle. For higher engine speeds (TP3 and TP4), considerable reduction in the smoke levels is observed with the cluster. The reductions for the lowest emissions for TP3 and TP4 are 18.6 per cent and 33.8 per cent respectively. Although the reductions are not the same for all the injection timings, the cluster (case 02) does show 


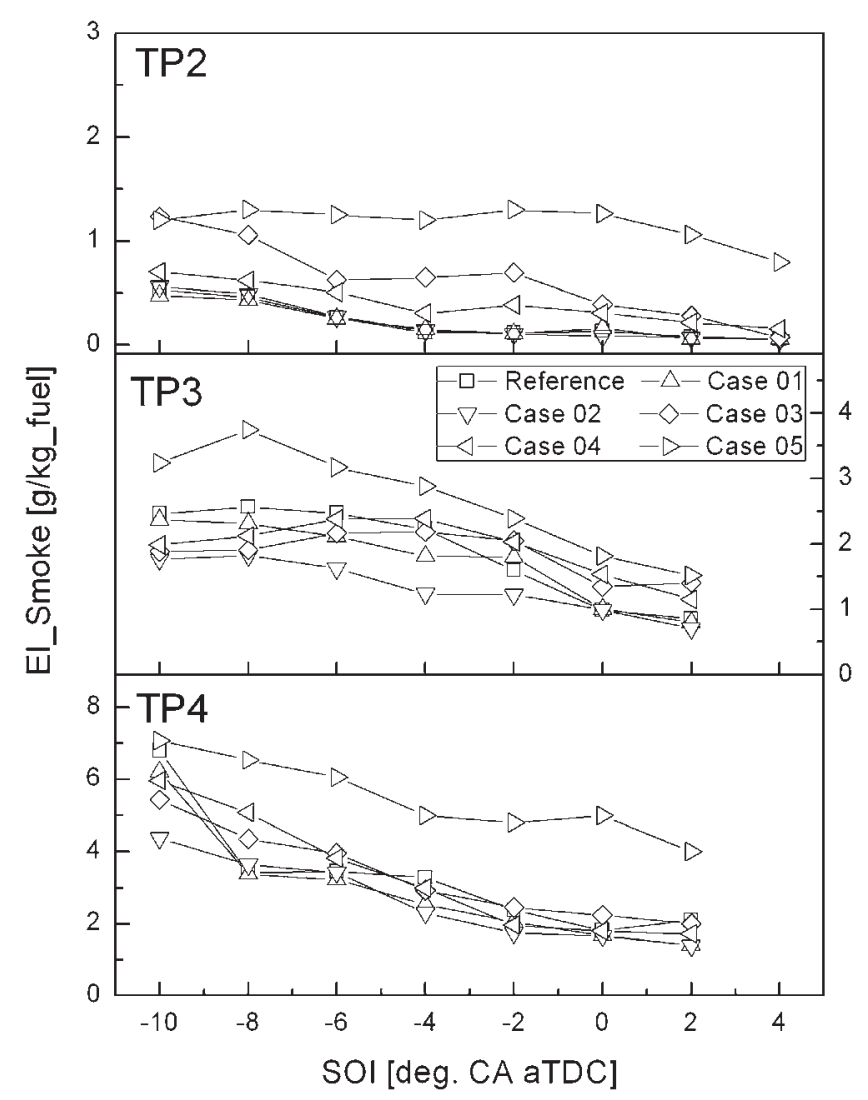

Fig. 19 Emission index of smoke (EI_Smoke) versus SOI for cluster $14 \times 158 / 158$ compared with the reference nozzle for TP2, TP3, and TP4

generally lower smoke emissions and better fuel consumption than the reference nozzle does for all injection timings and test points.

\section{SUMMARY AND CONCLUSION}

A modified piston bowl was designed for use with cluster nozzles. The modifications mainly include a smaller diameter, a larger bowl depth, and a larger toroidal radius. Four different clusters were measured for both the original bowl and the modified bowl for four different test points, and the results were compared with the reference nozzle. A cluster with the best results for smoke emissions in the first set of tests was also tested for three different swirl ratios and two different NTP lengths with the new bowl.

1. Heat release rates for clusters are higher during premixed combustion and lower during mixingcontrolled combustion. The ignition delay is shorter while the heat release rates are higher during premixed combustion with the new bowl.

2. Under PCCI conditions, there is no strong effect for emissions and fuel consumption of the bowl geometry and all the results are very similar for both the bowl geometries.

3. The vertical clusters have generally higher smoke emission than the horizontal clusters and the reference nozzle for both the bowl geometries.

4. Under high-engine-speed high-load conditions, the clusters show an improvement in the smoke emissions for the modified bowl. The larger toroidal radius and the smaller throat diameter of the modified bowl help to redirect the sprays along the wall towards the centre of the bowl.

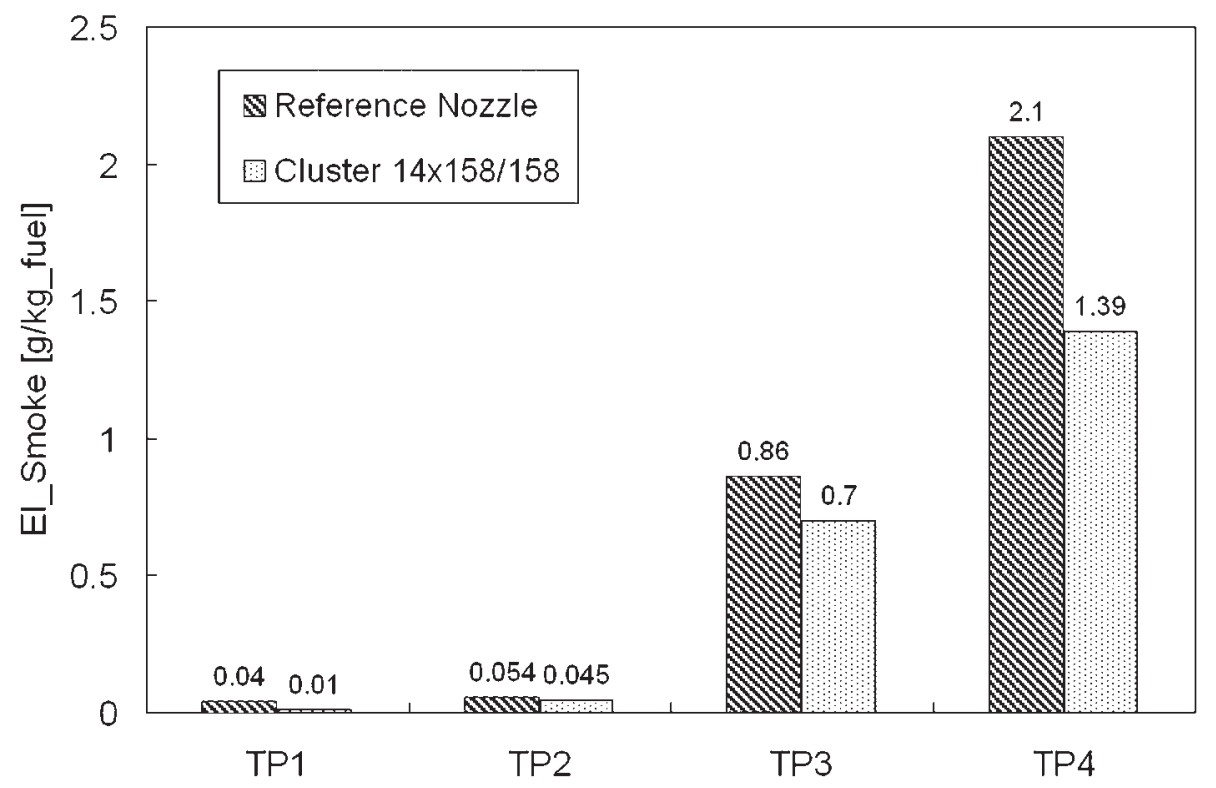

Fig. 20 Reduction in the emission index of smoke (EI_Smoke) with cluster $14 \times 158 / 158$ compared with the reference nozzles for TP1, TP2, TP3, and TP4 
5. For all test points, cluster $14 \times 158 / 158$ with the modified bowl (with $1.5 \mathrm{MSR}$ and $3 \mathrm{~mm}$ shim) shows the lowest emissions. For the low-load condition, it further reduces the emissions which were already low with the reference nozzle, while it shows a considerable reduction in the smoke emissions over the reference nozzle (with the original bowl) of 18.6 per cent and 33.8 per cent for TP3 and TP4 respectively.

Cluster $14 \times 158 / 158$ with the modified bowl consistently shows lower smoke emissions and better fuel consumption than the reference nozzle for all injection timings and test points. This provides a possible alternative for the diesel engines to solve the problem of high smoke emissions under highload operation.

\section{ACKNOWLEDGEMENTS}

This work was financially supported by General Motors Research and Development. The authors would like to thank the working group of the GM Collaborative Research Laboratory at RWTH Aachen University for their support and contribution.

(c) Authors 2010

\section{REFERENCES}

1 Bianchi, G. M., Pelloni, P., Corcione, F. E., Mattarelli, E., and Bertoni, F. L. Numerical study of the combustion chamber shape for common rail H.S.D.I. diesel engines. SAE paper 2000-01-1179, 2000.

2 Inagaki, K., Takasu, S., and Nakakita, K. Incylinder quantitative soot concentration measurement by laser-induced incandescence. SAE paper 1999-01-0508, 1999.

3 Montajir, R. M., Tsunemoto, H., Ishitani, H., and Minami, T. Fuel spray behavior in a small DI diesel engine: effect of combustion chamber geometry. SAE paper 2000-01-0946, 2000.

4 Zhu, Y., Zhao, H., Melas, D. A., and Ladommatos, N. Computational study of the effects of the geometry of the piston bowl pip for a high-speed direct injection diesel engine. Proc. IMechE, Part D: J. Automobile Engineering, 2004, 218(8), 875-890. DOI: 10.1243/0954407041581138.

5 Lin, L., Shulin, D., Jin, X., Jinxiang, W., and Xiaohong, G. Effects of combustion chamber geometry on in-cylinder air motion and performance in DI diesel engine. SAE paper 2000-01-0510, 2000.

6 Dahlén, L. Topics related to combustion and emissions formation in direct injected diesel en- gines, vol.1, Soot mediated oil thickening. Licentiate Thesis, ISRN/KTH/MMK/R-00/21-SE, TRITAMMK 2000:21, Department of Machine Design, Kungliga Tekniska Högskolan, Stockholm, Sweden, 2000.

7 Zhu, Y., Zhao, H., and Ladommatos, N. Computational fluid dynamics study of the effects of the reentrant lip shape and toroidal radii of piston bowl on a high-speed direct-injection diesel engine's performance and emissions. Proc. IMechE, Part D: J. Automobile Engineering, 2005, 219(8), 1011-1023. DOI: 10.1243/095440705X34649.

8 Genzale, L. C. and Reitz, D. R. Effects of piston bowl geometry on mixture development and lateinjection low-temperature combustion in a heavyduty diesel engine. SAE paper 2008-01-1330, 2008.

9 Middlemiss, I. D. Characteristics of the Perkins 'squish lip' direct injection combustion system. SAE paper 780113, 1978.

10 Saito, T., Daisho, Y., Uchida, N., and Ikeya, N. Effects of combustion chamber geometry on diesel combustion. SAE paper 861186, 1986.

11 Ikegami, M., Fukuda, M., Yoshihara, Y., and Kneko, J. Combustion chamber shape and pressurized injection in high-speed direct-injection diesel engine. SAE paper 900440, 1990.

12 Kidoguchi, Y., Yang, C., and Miwa, K. Effect of high squish combustion chamber on simultaneous reduction of $\mathrm{NO}_{x}$ and particulate from a direct-injection diesel engine. SAE paper 1999-011502, 1999.

13 Gao, J., Matsumoto, Y., and Nishida, K. Effects of group-hole nozzle specifications on fuel atomization and evaporation of direct injection diesel spray. SAE paper 2007-01-1889, 2007.

14 Nishida, K., Gao, J., and Matsumoto, Y. Experimental study on spray and mixture properties of the group-hole nozzle for direct-injection diesel engines. Part II: effects of included angle and interval between orifices. J. Atomization Sprays, 2009, 19(4), 339-355.

15 Nishida, K., Nomura, S., and Matsumoto, Y. Spray and mixture properties of group-hole nozzle for D.I. diesel engines. In Proceedings of the Tenth International Conference on Liquid atomization and spray systems (ICLASS-2006), Kyoto, Japan, 27 August-1 September 2006, paper ICLASS06-171, 2006 (available on CD).

16 Gao, J., Matsumoto, Y., and Nishida, K. Experimental study on spray and mixture properties of the group-hole nozzle for direct-injection diesel engines. Part I: a comparative analysis with the single-hole nozzle. J. Atomization Sprays, 2009, 19(4), 321-337.

17 Gao, J., Matsumoto, Y., Namba, M., and Nishida, K. Group-hole nozzle effects on mixture formation and in-cylinder combustion processes in directinjection diesel engines. SAE paper 2007-01-4050, 2007.

18 Gao, J., Matsumoto, Y., Namba, M., and Nishida, K. An investigation of mixture formation and in- 
cylinder combustion processes in direct injection diesel engines using group-hole nozzles. Int. J. Engine Res., 2009, 10(1), 27-44. DOI: 10.1243/ 14680874JER02108.

19 Zhang, Y., Nishida, K., Nomura, S., and Ito, T. Spray characteristics of group hole nozzle for D.I. diesel engine. SAE paper 2003-01-3115, 2003.

20 Won, H. W., Sharma, A., Hottenbach, P., Gauding, M., Robert, F. X., Peters, N., Gruenefeld, G., Durrett, R., Plazas, A., and Singh, S. Investigation of particulate emissions for cluster-nozzle concepts in DI diesel engines. In Proceedings of the 11th International Conference on Liquid atomization and spray systems (ICLASS-2009), Vail, Colorado, USA, 26-30 July 2009, paper ICLASS 2009-148.

21 Won, H. W., Sharma, A., Moon, S. E., Vanegas, A. and Peters, N. An experimental study of cluster nozzles for a DI diesel engine. SAE paper 2009-240053, 2009.

22 Won, H. W. and Peters, N. Investigation of clusternozzle concepts for diesel engines. J. Atomization Sprays, 2009, 19(10), 983-996.

23 Won, H. W. and Peters, N. Optimizing the injection pressure for cluster nozzle concepts in a direct injection diesel engine. Int. J. Engine Res., 2010, 11 (2), 163-175. DOI: 10.1243/14680874JER05409.

24 Pawlowski, A., Kneer, R., Lippert, A. M., and Parrish, S. E. Investigation of the interaction of sprays from clustered orifices under ambient conditions relevant for diesel engines. SAE paper 2008-01-0928, 2008.

25 Hottenbach, P., Gruenefeld, G., and Brands, T. An experimental investigation of combustion and soot formation of sprays from cluster nozzles for D.I. diesel engines. SAE paper 2009-01-0855, 2009.

26 Cardenas, M., Hottenbach, P., Kneer, R., and Gruenefeld, G. Investigations of clustered diesel jets under quiescent high-pressure and hightemperature conditions using Mie, Schlieren and chemiluminescence imaging. SAE paper 2009-012771, 2009.

27 Luckhchoura, V., Pardeshi, R., Cardenas, M., Vogel, S., Kneer, R., and Peters, N. Investigation of the opening angle between two sprays in diverging nozzles. In Proceedings of the 23rd Annual Conference on Liquid atomization and spray systems (ILASS-Europe 2010), Brno, Czech Republic, 6-8 September 2010.

28 Sjoeberg, M. Correlation between flame pattern, heat-release and emissions for a DI diesel engine with rotation injector and variable swirl. SAE paper 2001-01-2003, 2001.

29 Won, H. W. and Peters, N. The effects of swirl for the cluster nozzles in DI diesel engines. Int. J. Engine Res. (submitted for publication). 